\title{
HBV Infection Status and the Risk of Cholangiocarcinoma in Asia: A Meta-Analysis
}

\author{
Hao Zhang, ${ }^{1}$ Biqing Zhu, ${ }^{2}$ He Zhang, ${ }^{1}$ Jianxin Liang, ${ }^{1}$ and Wenting Zeng1 \\ ${ }^{1}$ Department of Infectious Diseases, The First Affiliated Hospital of Guangzhou Medical University, \\ Guangzhou Medical University, Yanjiang Road 151, Guangzhou 510120, China \\ ${ }^{2}$ Department of Laboratory Medicine, Dongguan Hospital of Traditional Chinese Medicine, \\ Guangzhou University of Chinese Medicine, Songshan Lake Avenue 22, Dongcheng District, Dongguan 523000, China
}

Correspondence should be addressed to Wenting Zeng; 13609645855@163.com

Received 15 March 2016; Accepted 6 June 2016

Academic Editor: Shinichi Aishima

Copyright (C) 2016 Hao Zhang et al. This is an open access article distributed under the Creative Commons Attribution License, which permits unrestricted use, distribution, and reproduction in any medium, provided the original work is properly cited.

Background. The inconsistent finding was between hepatitis B virus (HBV) infections and cholangiocarcinoma (CCA). This metaanalysis is to explore this relationship in Asia. Methods. A literature search was performed using PubMed, Web of Science, and Cochrane Library to October 30, 2015. Pooled incidence rate and OR with 95\% CI were calculated using STATA 11.0. Results. Thirty-nine studies were included. The pooled incidence rate of CCA patients with HBV infection was 31\% (95\% CI 22\%-39\%). The pooled OR showed increased risk of CCA incidence with HBV infection (OR $=2.72,95 \%$ CI $1.90-3.88)$, especially in ICC $(\mathrm{OR}=3.184,95 \%$ CI 2.356-4.302), while it showed no risk in ECC (OR $=1.407,95 \%$ CI $0.925-2.141)$. Also, the pooled OR showed increased risk of ICC and ECC incidence $(\mathrm{OR}=6.857,95 \%$ CI $4.421-10.633$ and OR $=1.740,95 \%$ CI $1.260-2.404)$ in patients with $\mathrm{HBs} A g+/ \mathrm{HBcAb}+$. The pooled OR showed increased risk of ICC incidence (OR $=1.410,95 \% \mathrm{CI} 1.095-1.816)$ in patients with $\mathrm{HBsAg}-/ \mathrm{HBcAb}+$. Conclusion. It is suggested that HBV infection is associated with an increased risk of CCA in Asia. Two HBV infection models $(\mathrm{HBsAg}+/ \mathrm{HBcAb}+$ and $\mathrm{HBsAg}-/ \mathrm{HBcAb}+)$ increase the risk of $\mathrm{CCA}$, and patients with $\mathrm{HBsAg}-/ \mathrm{HBcAb}+\mathrm{also}$ had a risk of ICC. This trial is registered with PROSPERO CRD42015029264.

\section{Introduction}

Cholangiocarcinoma (CCA) is the second commonest primary liver tumor worldwide after hepatocellular carcinoma (HCC) [1]. In the World Health Organization (WHO), CCA is classified as intrahepatic cholangiocarcinoma (ICC) or extrahepatic cholangiocarcinoma (ECC). It accounts for $3 \%$ of all gastrointestinal tumors [2]. During the past 3 decades, the overall incidence rate of CCA has appeared to have significantly increased [1]. Hepatobiliary malignancies account for $13 \%$ of cancer-related deaths and $10 \%-20 \%$ of these are attributable to CCA worldwide [3]. Currently, CCA has not been extensively investigated, possibly as a result of its presumptive rarity and worrisome prognosis at the time of diagnosis. It has been shown that CCA is characterized by a low survival rate with a median survival of less than 24 months after diagnosis [4].
Defining the risk factors for CCA benefits the search for better ways to prevent the occurrence of this disease. To date, it has been shown that viral infection (mainly hepatitis B and hepatitis C infection), gallstone formation, choledochoenteric anastomosis, oil sands carcinogenicity, chemicals and radiations exposure, biliary system development abnormalities, and so on are the major risk factors for CCA [5]. However, data from low hepatitis B (HBV) epidemic area and HBV infection is not a risk factor for CCA [6]. Thus, we conducted this meta-analysis for evaluating the association between HBV infection and CCA (including ICC and ECC) in Asian countries which are high HBV epidemic areas.

Also, two main treatment options in hepatitis B are available: interferon and nucleos(t)ide analogue (NUCs). There are five NUCs currently approved for HBV treatment: lamivudine (LAM), adefovir (ADV), telbivudine (LdT), 
entecavir (ETV), and tenofovir disoproxil fumarate (TDF). Treatment with TDF or ETV is more effective due to a high antiviral potency and has a high barrier to resistance reducing the risk of drug resistance and treatment failure [7]. So, HBV DNA could be inhibited during treatment. Even, some patients could achieve serological conversion of $\mathrm{HBsAg}(\mathrm{HBs} \mathrm{Ag}-/ \mathrm{HBcAb}+)$ whereas, for patients with curative resection of $\mathrm{HBV}$-related $\mathrm{HCC}$, positive $\mathrm{HBcAb}$ is associated with higher risk of early recurrence and poorer survival [8] and hepatitis B reactivation in $\mathrm{HBsAg}-/ \mathrm{HBcAb}+$ patients receiving rituximab for lymphoma [9]. According to those, the risk of cancer was still existing in patients with $\mathrm{HBsAg}-/ \mathrm{HBcAb}+$. Thus, this meta-analysis was also conducted for the association between HBV infection model and CCA risk.

\section{Methods}

2.1. Search Strategy. We have registered this trial with PROSPERO (http://www.crd.york.ac.uk/PROSPERO/) (trial number: CRD42015029264). Our study was performed according to the recommendations of the Moose [10] (see Supplementary Table 1 of the Supplementary Material available online at http://dx.doi.org/10.1155/2016/3417976). PubMed was searched combining the terms of ("hepatitis B" OR HBV OR CHB) AND ("bile duct neoplasms" OR cholangiocarcinoma).

2.2. Inclusion and Exclusion Criteria. For estimating the incidence rate of CCA, ICC, or ECC, the studies were included if they meet the criteria as follows: (i) studies only containing the cancer group; (ii) exposure to HBV infection; (iii) providing enough information for calculating the incidence rate; and (iv) the number of cases being not less than 50 .

For estimating the OR of CCA, ICC, or ECC, the studies were included if they meet the criteria as follows: (i) exposure to HBV infection; (ii) the outcome being CCA, ICC, or ECC incidence; (iii) providing risk estimates with $95 \%$ confidence interval (CI) or available information to calculate them; and (iv) published full-text report in English language.

Abstracts and reviews, letters, case reports, and studies that did not provide sufficient data to calculate the risk estimates were excluded. Two investigators (Hao Zhang and Biqing Zhu) independently selected studies, and any discrepancies were resolved by the third investigator (Wenting Zeng).

2.3. Quality Assessment. The quality of the included studies was assessed independently by two authors (Hao Zhang and Jianxin Liang) using the Newcastle-Ottawa Scale (NOS) [46]. The NOS is for observed studies and consists of 3 parameters of quality: selection, comparability, and exposure/outcome assessment. The NOS assigns a maximum of 4 points for selection, 2 for comparability, and 3 for exposure or outcome. We assigned NOS scores of 1-3, 4-6, and 7-9 for low-, intermediate-, and high-quality studies. Discrepancies were settled by consensus after joint reevaluation of the original studies with the third author (Jianxin Liang).
2.4. Data Extraction. The following information was extracted from each study: first author, publication time, the sample size, country, number of exposures in cases and controls; risk estimate; and 95\% CI. The data were collected independently by two investigators (Hao Zhang and Biqing Zhu). When the literature citations were controversial, these investigators discussed them and reached a consensus on inclusion or exclusion.

2.5. Data Analysis. The overincidence rate of CCA, ICC, and ECC with HBV infection was calculated by effect size (ES) and the corresponding 95\% confidence interval (95\% CI). The risk of HBV infection outcomes was estimated by odds ratio (OR) with the corresponding 95\% CI. It was considered statistically significant when $P<0.05$. In the forest plots, $\mathrm{OR}>1$ represented a risk effect and $\mathrm{OR}<1$ represented a protective effect. Statistical heterogeneity of results was appraised using a Chi-Square based $Q$ test and $I^{2}$ statistic. Only when the analysis fullfilled both $P>0.10$ and $I^{2}<50 \%$, the heterogeneity was considered not significant. The fixedeffects model was used when literature heterogeneity did not exist; otherwise, the random-effects model was employed. Sensitivity analysis was conducted by modification of the inclusion criteria of this meta-analysis. The pooled proportion of vertical transmission of toxoplasmosis was calculated by STATA 11.0 software (Stata Corporation, College Station, TX, USA) and the publication bias was considered significant when $P$ value was less than 0.05 in either Begg's test or Egger's test.

\section{Results}

3.1. Selection of Studies. A flow diagram of the selection of the studies is shown in Figure 1. A total of 39 studies with CCA matched the inclusion criteria in this meta-analysis, including 21 studies [11-31] for estimating the incidence rates of CCA, 14 studies [32-45] for unadjusted OR, and 7 studies $[32,33,36,39,41,42,44]$ for adjusted OR analysis (Tables 1 and 2). Among the 39 studies, 26 studies were for ICC, including 13 studies [11-14, 16, 17, 19, 22, 23, 25, 26, 29, 31] for estimating the incidence rates of ICC, 11 studies [32, 3436, 39-42, 44, 45, 47] for unadjusted OR analysis, and 7 studies [32, 35, 36, 39, 41, 42, 44] for adjusted OR analysis (Tables 3 and 4). Nine studies were for ECC, including 3 studies $[11,15,20]$ for estimating the incidence rates of ECC, 5 studies [32, 35, 40, 43, 47] for unadjusted OR analysis, and 1 study [35] for adjusted OR analysis (Tables 4 and 5). The main features of included studies were shown in Tables 1-5. Among the included studies, 4 studies are from Korea [24, 29, 32, 43], 4 from Japan [11, 28, 30, 45], 3 from Thailand [18, 30, 38], and 24 from China [12-17, 19-23, 25-27, 33-37, 39-43]. For analyzing the association between $\mathrm{HBV}$ infection and CCA risk, twelve studies (75\%) were of high quality and the other four (25\%) were acceptable based on the NOS scores.

3.2. HBV Infection and the Risk of CCA. For pooled analysis of incidence rates of CCA with HBV infection, 21 studies with 6253 participants were included [11-31]. All these studies 
TABLE 1: Incidence rate of studies of HBV infection and CCA.

\begin{tabular}{|c|c|c|c|c|c|}
\hline Authors & Year & Country & HBV infection cases $(n)$ & CCA cases $(n)$ & Reference \\
\hline Matsumoto et al. & 2014 & Japan & 29 & 145 & {$[11]$} \\
\hline Luo et al. & 2014 & China & 608 & 1233 & {$[12]$} \\
\hline Liu et al. & 2013 & China & 37 & 81 & [13] \\
\hline Yin et al. & 2013 & China & 139 & 411 & {$[14]$} \\
\hline Zhou et al. & 2013 & China & 88 & 239 & {$[15]$} \\
\hline Wu et al. & 2013 & China & 97 & 138 & {$[16]$} \\
\hline Lee et al. & 2013 & China (Taiwan) & 29 & 127 & {$[17]$} \\
\hline Barusrux et al. & 2012 & Thailand & 24 & 295 & {$[18]$} \\
\hline Yin et al. & 2012 & China & 131 & 386 & {$[19]$} \\
\hline Qu et al. & 2012 & China & 19 & 305 & {$[20]$} \\
\hline Wu et al. & 2012 & China & 18 & 66 & {$[21]$} \\
\hline Jiang et al. & 2011 & China & 44 & 102 & {$[22]$} \\
\hline Zhou et al. & 2011 & China & 87 & 155 & {$[23]$} \\
\hline Park et al. & 2011 & Korea & 32 & 160 & {$[24]$} \\
\hline Zhou et al. & 2010 & China & 154 & 317 & {$[25]$} \\
\hline Zhou et al. & 2008 & China & 64 & 131 & {$[26]$} \\
\hline Zuo et al. & 2007 & China & 20 & 59 & {$[27]$} \\
\hline Fukuhara et al. & 2001 & Japan & 4 & 53 & {$[28]$} \\
\hline Lee et al. & 2006 & Korea & 11 & 79 & {$[29]$} \\
\hline Pinyosophon and Wiwanitkit & 2002 & Thailand & 5 & 55 & {$[30]$} \\
\hline Asayama et al. & 2002 & Japan & 8 & 68 & {$[31]$} \\
\hline
\end{tabular}

TABLE 2: Characteristics of studies of HBV infection and CCA risk.

\begin{tabular}{|c|c|c|c|c|c|c|c|c|}
\hline Authors & Year & Country & Cases $(n)$ & Controls $(n)$ & Control description & $\begin{array}{c}\text { Adjusted OR } \\
(95 \% \mathrm{CI})\end{array}$ & Study quality & Reference \\
\hline Lee et al. & 2015 & Korea & 276 & 552 & Hospital-based control & $\begin{array}{c}4.12 \\
(2.01-8.44)\end{array}$ & 7 & {$[32]$} \\
\hline Zhou et al. & 2014 & China & 126 & 504 & Hospital-based control & $\begin{array}{c}19.245 \\
(13.260-27.931)\end{array}$ & 7 & {$[33]$} \\
\hline Li et al. & 2014 & China & 183 & 549 & Hospital-based control & NR & 8 & {$[34]$} \\
\hline Chang et al. & 2013 & China (Taiwan) & 5157 & 8716 & Population-based control & NR & 9 & {$[35]$} \\
\hline Peng et al. & 2011 & China & 98 & 196 & Hospital-based control & $\begin{array}{c}2.75 \\
(1.27-5.95)\end{array}$ & 8 & {$[36]$} \\
\hline Cai et al. & 2011 & China & 313 & 608 & Hospital-based control & NR & 7 & {$[37]$} \\
\hline $\begin{array}{l}\text { Srivatanakul et } \\
\text { al. }\end{array}$ & 2010 & Thailand & 106 & 106 & Population-based control & NR & 6 & {$[38]$} \\
\hline Zhou et al. & 2010 & China & 317 & 634 & Hospital-based control & $\begin{array}{c}9.669 \\
(6.329-14.77)\end{array}$ & 8 & {$[39]$} \\
\hline Tao et al. & 2010 & China & 190 & 380 & Hospital-based control & NR & 8 & {$[40]$} \\
\hline Lee et al. & 2009 & China (Taiwan) & 160 & 160 & Hospital-based control & $\begin{array}{c}4.985 \\
(2.775-8.945)\end{array}$ & 6 & {$[41]$} \\
\hline Zhou et al. & 2008 & China & 312 & 438 & Hospital-based control & $\begin{array}{c}8.876 \\
(5.973-13.192)\end{array}$ & 6 & {$[42]$} \\
\hline Hsing et al. & 2008 & China & 134 & 762 & Population-based control & NR & 8 & {$[43]$} \\
\hline Lee et al. & 2008 & Korea & 622 & 2488 & Hospital-based control & $\begin{array}{c}2.3 \\
(1.6-3.3)\end{array}$ & 7 & {$[44]$} \\
\hline Yamamoto et al. & 2004 & Japan & 50 & 200 & Hospital-based control & NR & 6 & {$[45]$} \\
\hline
\end{tabular}

\footnotetext{
NR: not reported.
} 
TABLE 3: Incidence rate of studies of HBV infection and ICC/ECC.

\begin{tabular}{|c|c|c|c|c|c|c|}
\hline Authors & Year & Country & Cancer group & HBV infection cases $(n)$ & CCA cases $(n)$ & Reference \\
\hline Matsumoto et al. & 2014 & Japan & ICC & 16 & 50 & [11] \\
\hline Luo et al & 2014 & China & ICC & 608 & 1233 & {$[12]$} \\
\hline Liu et al. & 2013 & China & ICC & 37 & 81 & {$[13]$} \\
\hline Yin et al. & 2013 & China & ICC & 139 & 411 & {$[14]$} \\
\hline Zhou et al. & 2013 & China & ECC & 88 & 239 & {$[15]$} \\
\hline Wu et al. & 2013 & China & ICC & 97 & 138 & {$[16]$} \\
\hline Lee et al. & 2013 & China (Taiwan) & ICC & 29 & 127 & [17] \\
\hline Yin et al. & 2012 & China & ICC & 131 & 386 & [19] \\
\hline Qu et al. & 2012 & China & ECC & 19 & 305 & {$[20]$} \\
\hline Jiang et al. & 2011 & China & ICC & 44 & 102 & {$[22]$} \\
\hline Zhou et al. & 2011 & China & ICC & 87 & 155 & [23] \\
\hline Zhou et al. & 2010 & China & ICC & 154 & 317 & {$[25]$} \\
\hline Zhou et al. & 2008 & China & ICC & 64 & 131 & {$[26]$} \\
\hline Lee et al. & 2006 & Korea & ICC & 11 & 79 & [29] \\
\hline Asayama et al. & 2002 & Japan & ICC & 8 & 68 & {$[31]$} \\
\hline
\end{tabular}

TABLE 4: Characteristics of studies of HBV infection and ICC risk.

\begin{tabular}{|c|c|c|c|c|c|c|c|c|}
\hline Authors & Year & Country & Cases $(n)$ & Controls $(n)$ & Control description & $\begin{array}{c}\text { Adjusted OR } \\
(95 \% \mathrm{CI})\end{array}$ & Study quality & Reference \\
\hline Lee et al. & 2015 & Korea & 83 & 166 & Hospital-based control & $\begin{array}{c}5.27 \\
(1.93-14.38)\end{array}$ & 7 & {$[32]$} \\
\hline Li et al. & 2014 & China & 183 & 549 & Hospital-based control & NR & 8 & {$[34]$} \\
\hline Chang et al. & 2013 & China (Taiwan) & 2978 & 11912 & Population-based control & $\begin{array}{c}3.5 \\
(2.9-4.3)\end{array}$ & 9 & {$[35]$} \\
\hline Wu et al. & 2012 & China & 102 & 835 & Hospital-based control & NR & 7 & {$[47]$} \\
\hline Peng et al. & 2011 & China & 98 & 196 & Hospital-based control & $\begin{array}{c}2.75 \\
(1.27-5.95)\end{array}$ & 8 & {$[36]$} \\
\hline Zhou et al. & 2010 & China & 317 & 634 & Hospital-based control & $\begin{array}{c}9.669 \\
(6.329-14.77)\end{array}$ & 8 & {$[39]$} \\
\hline Tao et al. & 2010 & China & 61 & 380 & Hospital-based control & NR & 8 & {$[40]$} \\
\hline Lee et al. & 2009 & China (Taiwan) & 160 & 160 & Hospital-based control & $\begin{array}{c}4.985 \\
(2.775-8.945)\end{array}$ & 6 & {$[41]$} \\
\hline Zhou et al. & 2008 & China & 312 & 438 & Hospital-based control & $\begin{array}{c}8.876 \\
(5.973-13.192)\end{array}$ & 6 & {$[42]$} \\
\hline Lee et al. & 2008 & Korea & 622 & 2488 & Hospital-based control & $\begin{array}{c}2.3 \\
(1.6-3.3)\end{array}$ & 7 & {$[44]$} \\
\hline Yamamoto et al. & 2004 & Japan & 50 & 200 & Hospital-based control & NR & 6 & {$[45]$} \\
\hline
\end{tabular}

TABLE 5: Characteristics of studies of HBV infection and ECC risk.

\begin{tabular}{|c|c|c|c|c|c|c|c|c|}
\hline Authors & Year & Country & Cases $(n)$ & Controls $(n)$ & Control description & Adjusted OR (95\% CI) & Study quality & Reference \\
\hline Lee et al. & 2015 & Korea & 193 & 386 & Hospital-based control & NR & 7 & {$[32]$} \\
\hline Chang et al. & 2013 & China (Taiwan) & 2179 & 8716 & Population-based control & $2.6(2.0-3.4)$ & 9 & [35] \\
\hline Zhou et al. & 2013 & China & 239 & 478 & Hospital-based control & NR & 7 & {$[15]$} \\
\hline Wu et al. & 2012 & China & 86 & 835 & Hospital-based control & NR & 7 & [47] \\
\hline Tao et al. & 2010 & China & 129 & 380 & Hospital-based control & NR & 8 & {$[40]$} \\
\hline Hsing et al. & 2008 & China & 134 & 762 & Population-based control & NR & 8 & {$[43]$} \\
\hline
\end{tabular}

NR: not reported. 


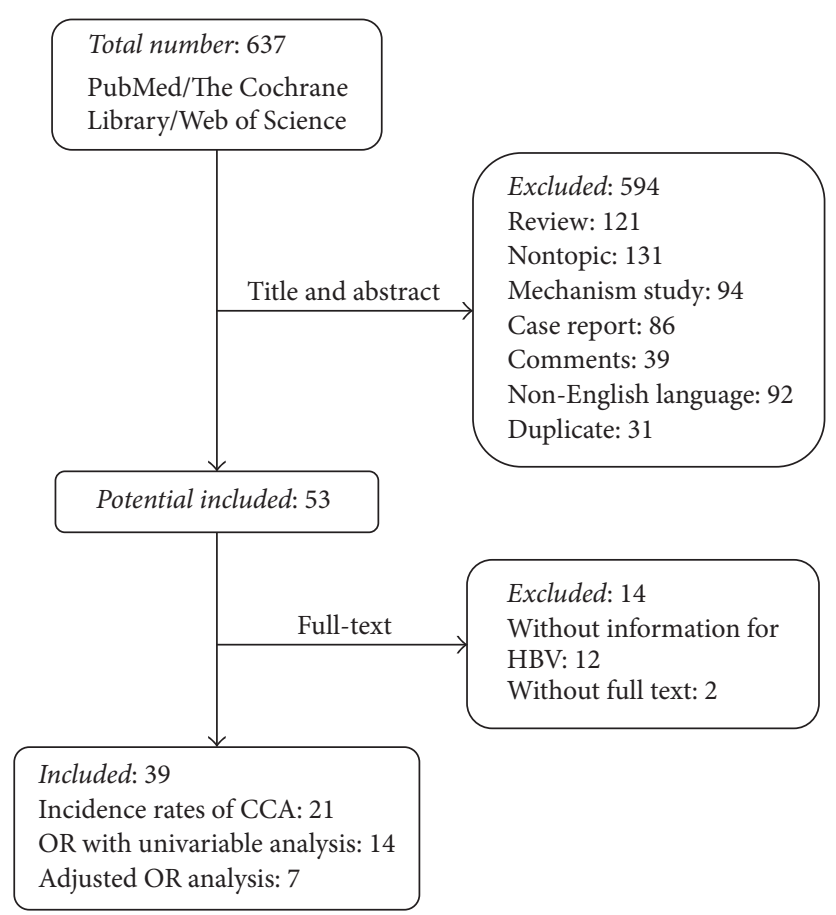

FIGURE 1: Flow diagram of selection and disposition of studies.

were from Asia, including 3 from Japan, 2 from Thailand, one from Korea, and 15 from China. The overall pooled incidence rates were $31 \%(95 \%$ CI $22 \%-39 \%)$, calculated with the random-effects model $\left(P<0.001, I^{2}=98.0 \%\right.$, Figure $\left.2(\mathrm{a})\right)$. In China, the pooled incidence rates were $37.6 \%(95 \% \mathrm{CI}$ $26.8 \%-48.3 \%, P<0.001)$, calculated with the random-effects model $\left(P<0.001, I^{2}=98.5 \%\right)$.

For pooled analysis of unadjusted OR of CCA with HBV infection, 14 studies with 24337 participants including controls were analyzed [32-45]. The meta-analysis in a randomeffects model $\left(P<0.001, I^{2}=91.2 \%\right)$ found statistically significant increased risk of CCA incidence with HBV infection $(\mathrm{OR}=2.72$, 95\% CI 1.90-3.88, $P<0.001$, Figure 2(b)). No publication bias was observed by Begg's test $(P=0.443)$ and Egger's test $(P=0.774)$. The sensitivity analysis showed that the result that $\mathrm{HBV}$ infection was a high risk for patients progressing into CCA was not changed (Figure 2(c)).

For pooled analysis of adjusted OR of CCA with HBV infection, 7 studies with 6,883 participants including controls were analyzed $[32,33,36,39,41,42,44]$. The meta-analysis in a random-effects model $\left(P<0.001, I^{2}=92.2 \%\right)$ also found statistically significant increased risk of CCA incidence with HBV infection $(\mathrm{OR}=5.903,95 \%$ CI 3.110-11.207, $P<0.001$, Figure 2(d)).

3.3. HBV Infection and the Risk of ICC. For pooled analysis of incidence rates of ICC with HBV infection, 13 studies with 4,871 participants were included $[11-14,16,17,19,22,23$, $25,26,29,31]$. All these studies were from Asia, including 2 were from Japan, 1 from Korea, and 10 from China. The overall pooled incidence rates were 39\% (95\% CI 32\%-46\%,
$P<0.001)$, calculated with the random-effects model $(P<$ $0.001, I^{2}=100 \%$, Figure 3(a)).

For pooled analysis of unadjusted OR of ICC with HBV infection, 11 studies with 22924 participants including controls were analyzed [32, 34-36, 39-42, 44, 45, 47]. The meta-analysis in a random-effects model $\left(P<0.001, I^{2}=\right.$ $84.0 \%)$ found statistically significant increased risk of ICC incidence with HBV infection (OR $=3.184$, 95\% CI 2.3564.302, $P<0.001$, Figure 3(b)). No publication bias was observed by Begg's test $(P=0.755)$ and Egger's test $(P=$ 0.428 ). The sensitivity analysis showed that the result that $\mathrm{HBV}$ infection was a high risk for patients progressing into ICC was not changed (Figure 3(c)).

For pooled analysis of adjusted OR of ICC with HBV infection, 7 studies with 20,564 participants including controls were analyzed $[32,35,36,39,41,42,44]$. The metaanalysis in a random-effects model $\left(P<0.001, I^{2}=\right.$ $86.4 \%)$ also found statistically significant increased risk of ICC incidence with $\mathrm{HBV}$ infection $(\mathrm{OR}=4.709,95 \% \mathrm{CI}$ 3.020-7.341, $P<0.001$, Figure 3(d)).

3.4. HBV Infection and the Risk of ECC. For pooled analysis of incidence rates of ECC with HBV infection, 2 studies with 483 participants were included $[11,20]$. These studies were from Japan and China. The overall pooled incidence rates were $18.9 \%$ (95\% $\mathrm{CI}-0.7 \%-38.5 \%, P=0.059)$, calculated with the random-effects model $\left(P<0.001, I^{2}=100 \%\right.$, Figure 4(a)).

For pooled analysis of unadjusted OR of ECC with HBV infection, 6 studies with 14517 participants including controls were analyzed $[15,32,35,40,43,47]$. The meta-analysis in 


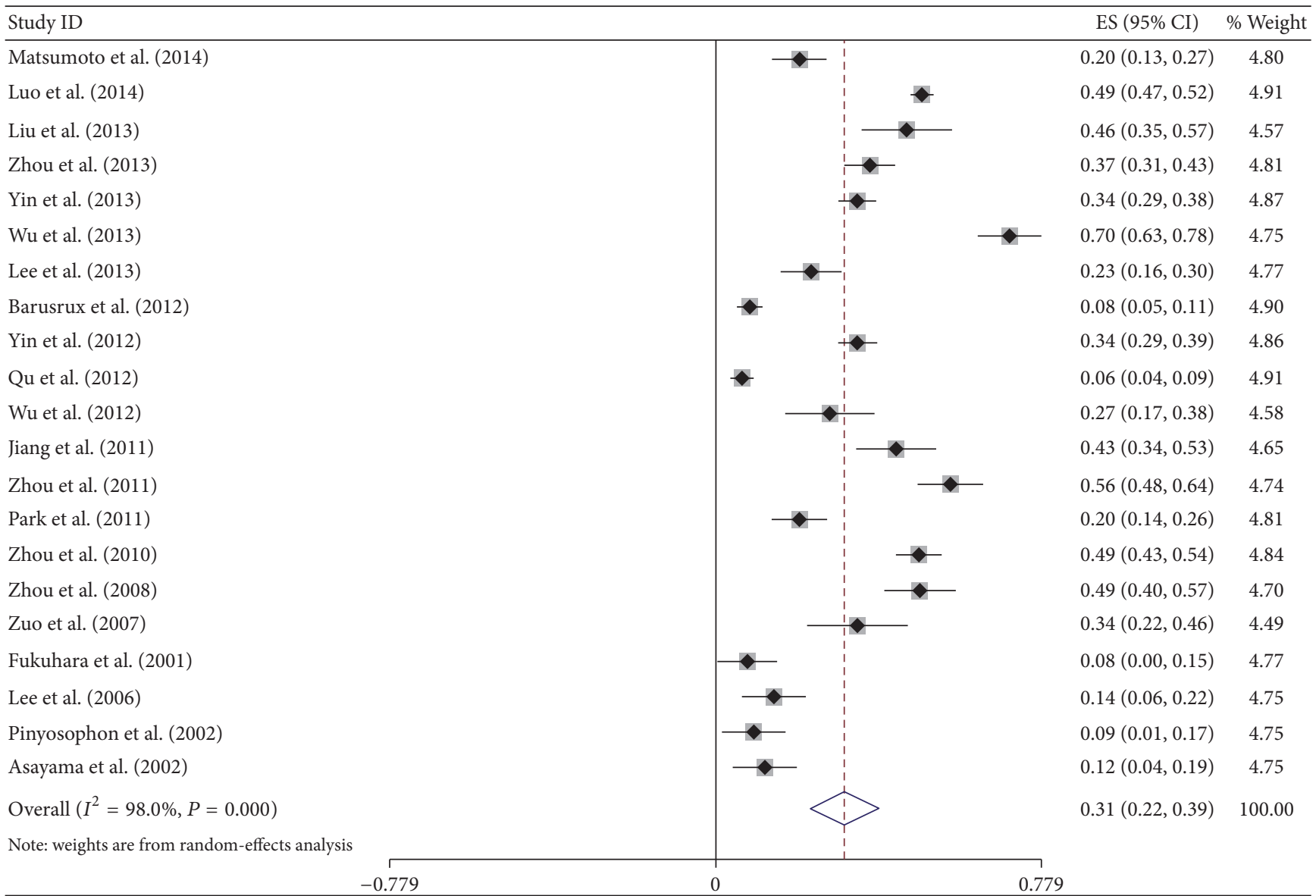

(a)

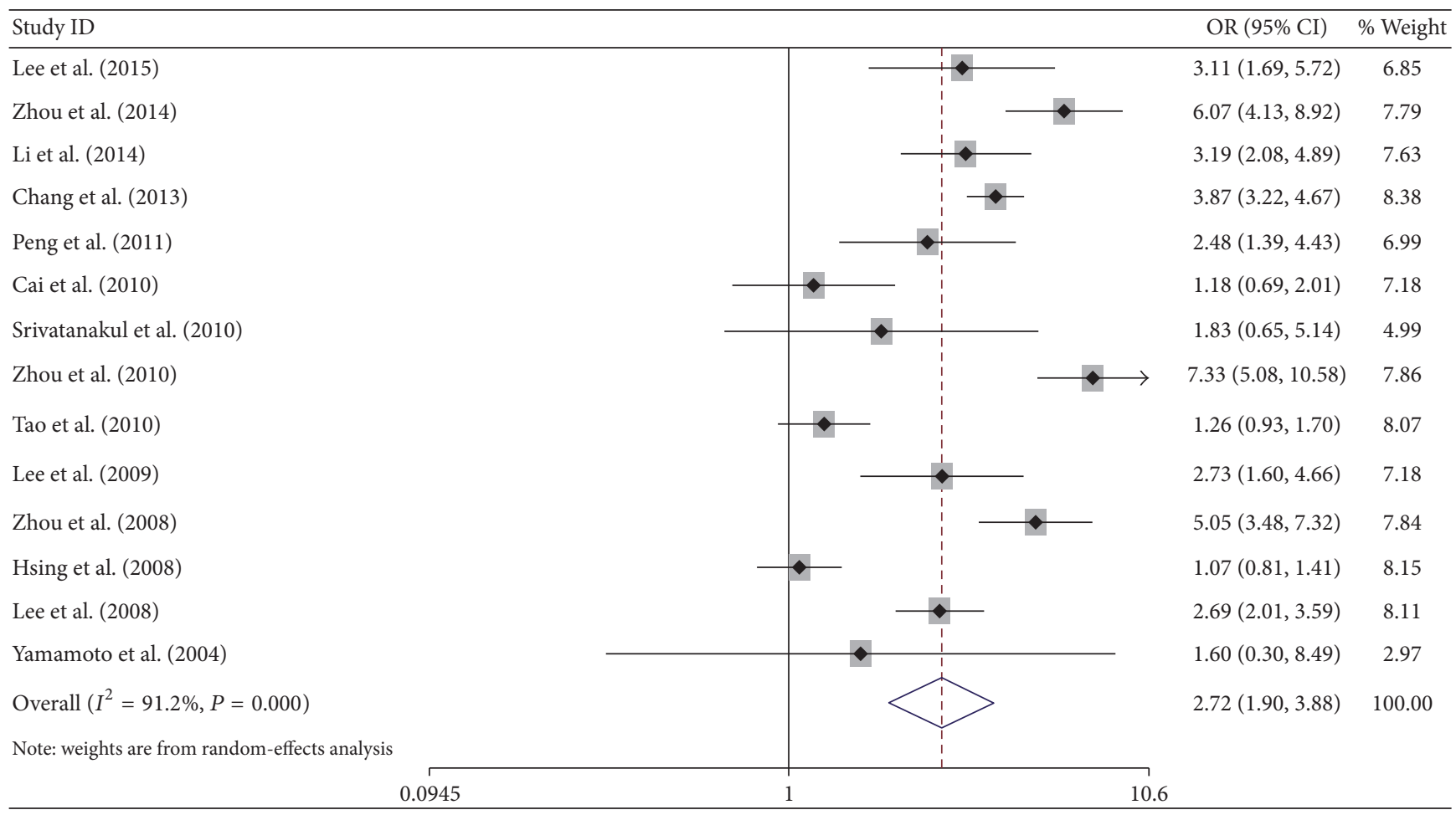

(b)

Figure 2: Continued. 


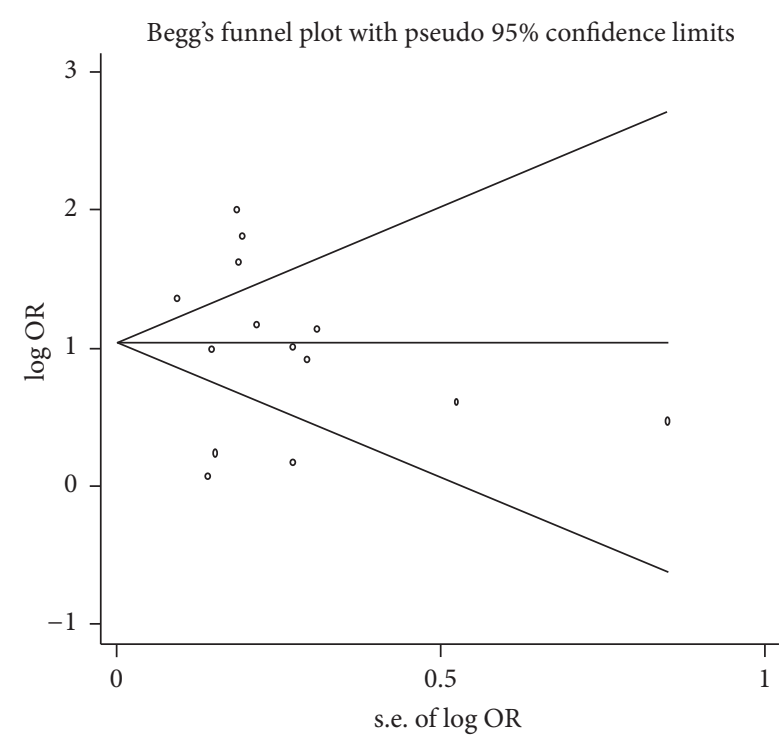

(c)

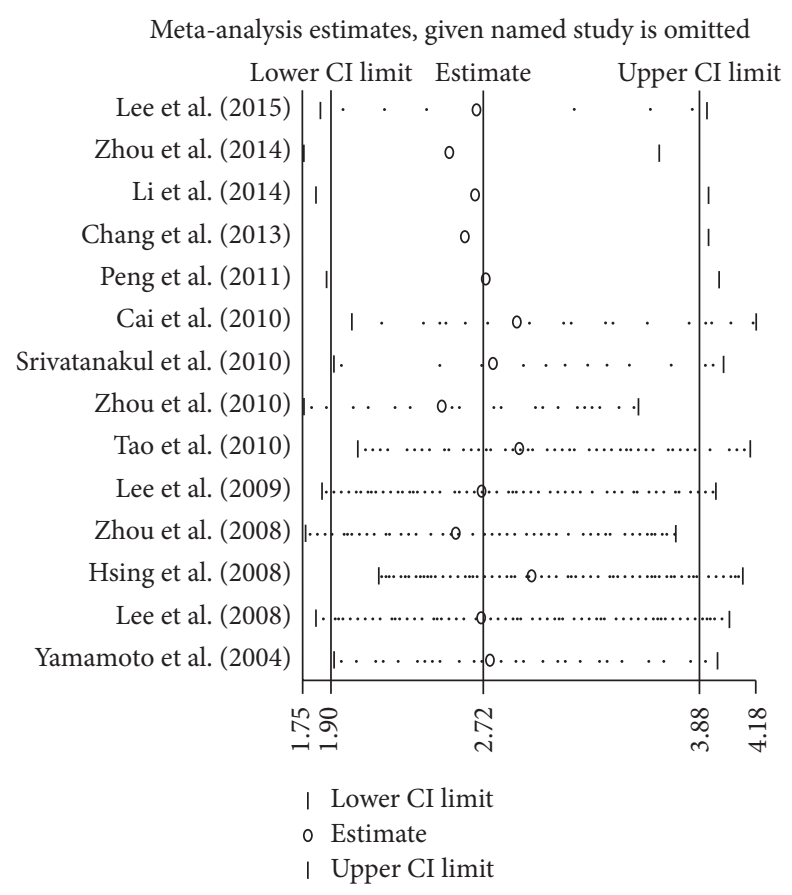

(d)

Figure 2: Meta-analysis of the association between HBV infection and CCA. (a) Pooled incidence of CCA in Asia; (b) forest plots of the association between HBV infection and CCA with unadjusted OR; (c) sensitivity analysis of the association between HBV infection and CCA; and (d) forest plots of the association between HBV infection and CCA with adjusted OR.

a random-effects model $\left(P<0.001, I^{2}=88.6 \%\right)$ found no statistically significant increased risk of ECC incidence with HBV infection $(\mathrm{OR}=1.407,95 \%$ CI 0.925-2.141, $P=0.110$, Figure 4(b)). No publication bias was observed by Begg's test $(P=1.0)$ and Egger's test $(P=0.579)$. The sensitivity analysis showed that the result that HBV infection was not a high risk for patients progressing into ECC was not changed (Figure 4(c)).

However, the adjusted OR of ECC with HBV infection found statistically significant increased risk of ECC incidence with $\mathrm{HBV}$ infection $(\mathrm{OR}=2.6,95 \%$ CI 2.0-3.4), which was only in one study [35].

3.5. HBV Infection Status and the Risk of Cancer. Two $\mathrm{HBV}$ infection models, which were $\mathrm{HBsAg}+/ \mathrm{HBcAb}+$ and $\mathrm{HBsAg}-/ \mathrm{HBcAb}+$, were included in this meta-analysis. Patients with $\mathrm{HBsAg}+/ \mathrm{HBcAb}+$ showed a high risk of ICC $(\mathrm{OR}=6.857,95 \%$ CI 4.421-10.633) with calculating in a fixeffects model $\left(P=0.447, I^{2}=0 \%\right.$, Figure 5(a)). As only two studies were analyzed, the publication bias and sensitivity analysis cannot be performed. The risk of ICC was increased in patients with $\mathrm{HBsAg}-/ \mathrm{HBcAb}+(\mathrm{OR}=1.410,95 \% \mathrm{CI}$ $1.095-1.816)$ with calculating in a fix-effects model $(P=0.202$, $I^{2}=37.4 \%$, Figure 5(b)). No publication bias was observed by Begg's test $(P=0.96)$ and Egger's test $(P=0.270)$. As only three studies were analyzed, the sensitivity analysis cannot be performed.
Patients with $\mathrm{HBsAg}+/ \mathrm{HBcAb}+$ showed a high risk of ECC $(\mathrm{OR}=1.740,95 \%$ CI 1.260-2.404) with calculating in a fix-effects model $\left(P=0.914, I^{2}=0 \%\right.$, Figure $\left.5(\mathrm{c})\right)$. No publication bias was observed by Begg's test $(P=0.734)$ and Egger's test $(P=0.627)$. The sensitivity analysis showed that the result that $\mathrm{HBV}$ infection was a high risk for patients progressing into ECC was not changed (Figure 5(d)). The risk of ECC was not increased of patients with $\mathrm{HBsAg}-/ \mathrm{HBcAb}+$ $(\mathrm{OR}=1.049,95 \%$ CI $0.881-1.249)$ with calculating in a fixeffects model $\left(P=0.382, I^{2}=2.1 \%\right.$, Figure $\left.5(\mathrm{e})\right)$. No publication bias was observed by Begg's test $(P=0.734)$ and Egger's test $(P=0.993)$. As only three studies were analyzed, the sensitivity analysis cannot be performed. The sensitivity analysis showed that the result that HBV infection was not a high risk for patients progressing into ECC was not changed (Figure 5(f)).

\section{Discussion}

HBV is widely epidemic in Asian countries [48]. Previous study has concluded that HBV infection is associated with an increased risk of ICC [49]. This meta-analysis was employed to estimate the CCA incidence rate in $\mathrm{HBV}$ infection patients and the CCA risk of HBV infection models in Asia, including ICC and ECC.

In this study, HBV infection leading to CCA was about $31 \%$, and this rate (39\%) was also high in China. HBV infection, where pooled OR is 2.72 (95\% CI $1.90-3.88)$ and 


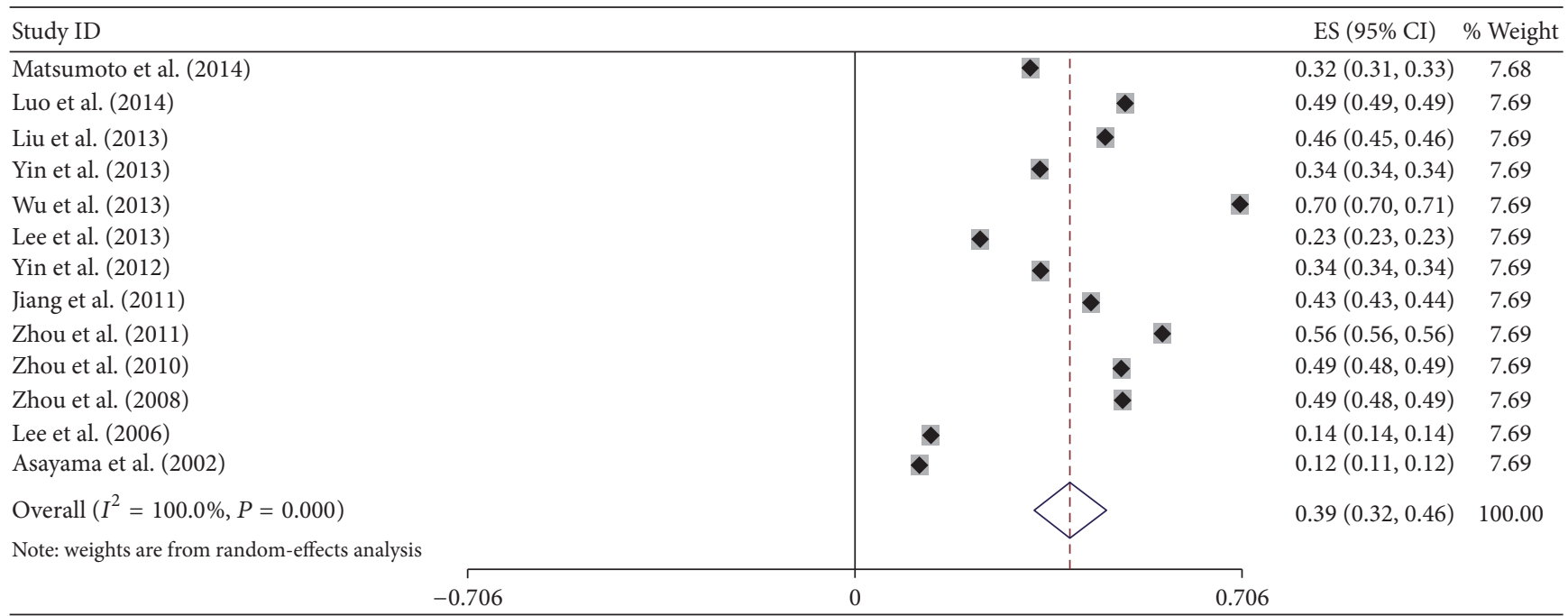

(a)

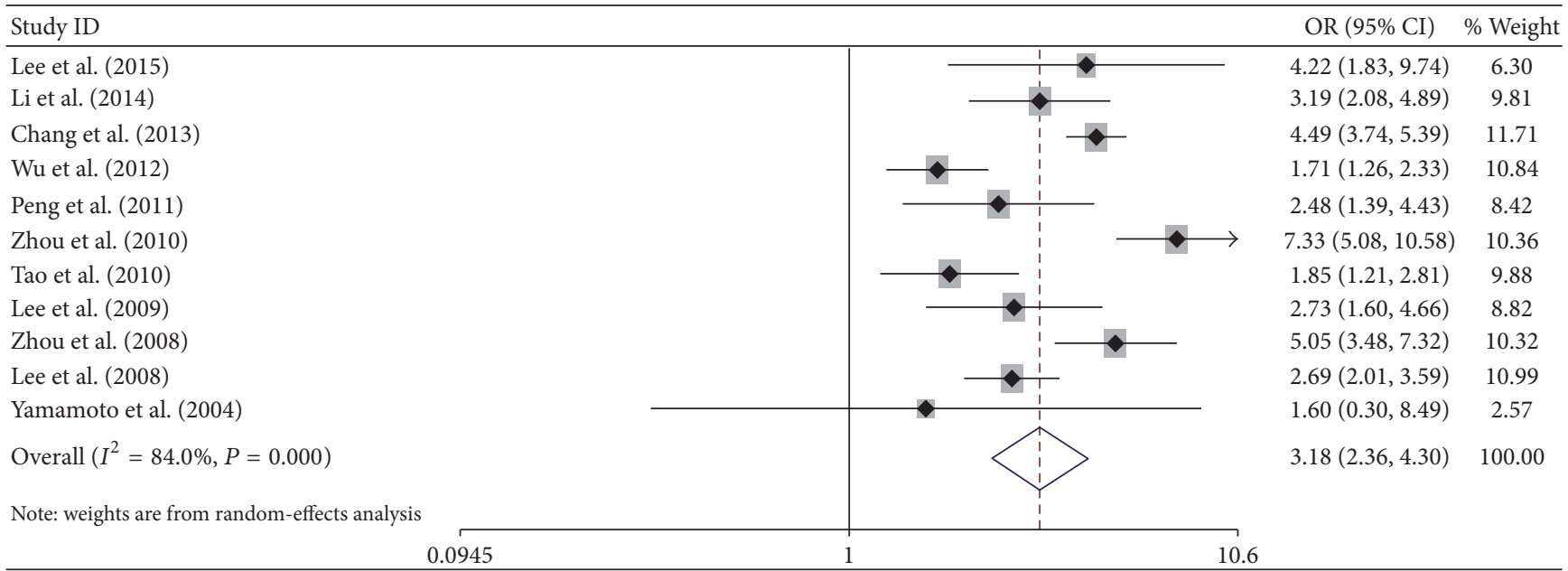

(b)

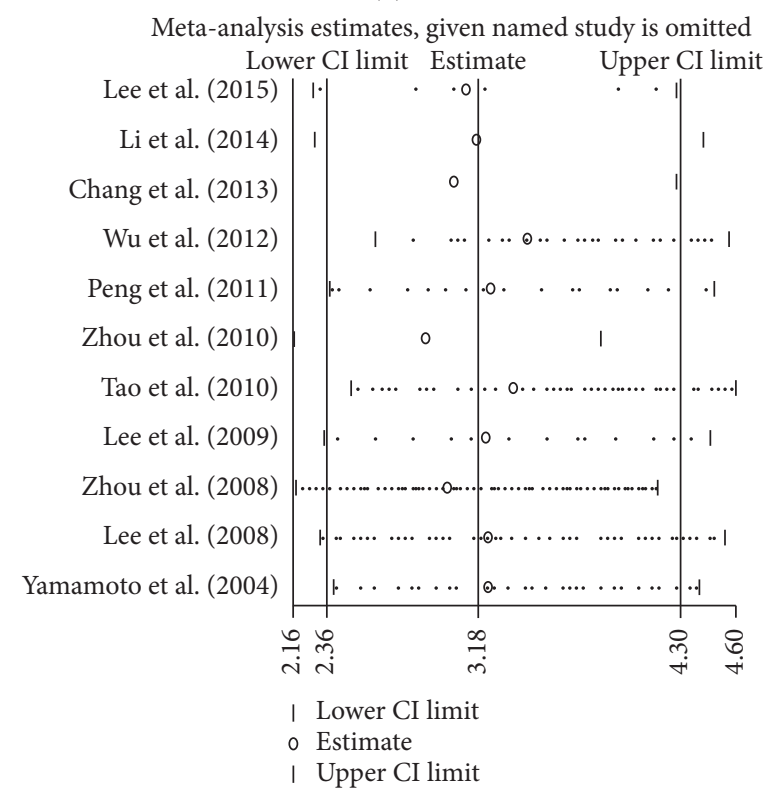

(c)

FIgUre 3: Continued. 


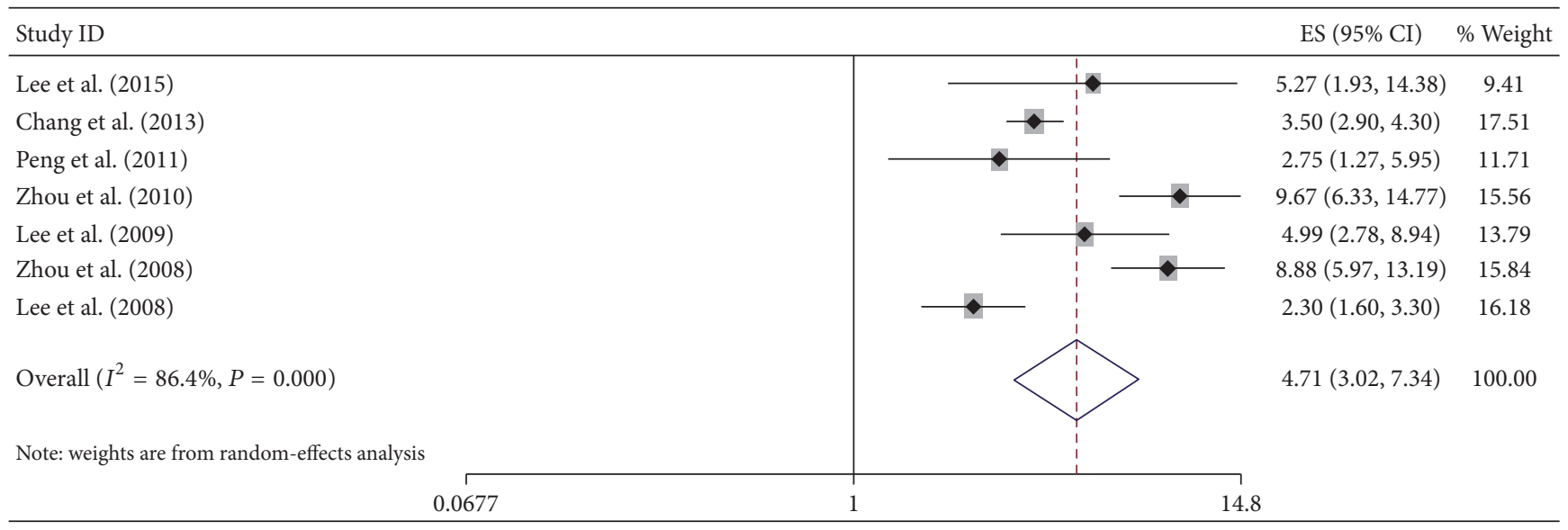

(d)

FIgURE 3: Meta-analysis of the association between HBV infection and ICC. (a) Pooled incidence of ICC in Asia; (b) forest plots of the association between HBV infection and ICC with unadjusted OR; (c) sensitivity analysis of the association between HBV infection and ICC; and (d) forest plots of the association between HBV infection and ICC with adjusted OR.

adjusted OR is 5.903 (95\% CI 3.110-11.207), is a risk factor of CCA. This phenomenon also occurred in the patients with ICC. As all we know, HBV is a strong risk factor for HCC. And hepatocytes and cholangiocytes have the same progenitor cell; therefore, it can be postulated that HBV can induce carcinogenesis in both hepatocytes and cholangiocytes by the same mechanism [50]. Furthermore, studies show that $\mathrm{HBV}$ has been suggested to be involved in the pathogenesis of ICC through the inflammatory process [51, 52], which further supports the potential role of $\mathrm{HBV}$ infection in the pathogenesis of cholangiocarcinoma. Also, recent clinical surveys in China have detected HBV DNA in the tissue species from bile duct cancer.

Interestingly, the risk of ICC was also excluded in patients with the model of $\mathrm{HBs} \mathrm{Ag}-/ \mathrm{HBcAb}+$ that termed non-B nonC. The main mechanism may be that these patients were occult HBV infection. It is reported that even a history of $\mathrm{HBV}$ infection (positive $\mathrm{HBcAb}+$ with $\mathrm{HBsAg}-$ ) can be a risk factor for HCC [53]. HBcAb positive status may reflect occult $\mathrm{HBV}$ infection and could be associated with an increase in the risk of carcinogenesis [54]. Also, a recent study reported that positive $\mathrm{HBcAb}$ is associated with a higher risk of early intrahepatic recurrence and poorer relapse-free survival of HBV-related HCC patients after curative resection [8], which means that $\mathrm{HBcAb}$ may play a role in the HCC patients.

Although the incidence rate of ECC was not significantly different in $\mathrm{HBV}$ infection patients and $\mathrm{HBV}$ infection was not a risk of patients progressing into ECC, the $\mathrm{HBV}$ infection status was much different. Patients with $\mathrm{HBsAg}+/ \mathrm{HBcAb}+$ showed a high risk of ECC, while patients with $\mathrm{HBsAg}-/ \mathrm{HBcAb}+$ showed no risk of ECC. The mechanism may be associated with HBsAg status. Though few studies have explained the link between HBsAg and ECC, a recent report showed that HBsAg could stimulate proliferation and functional modification of hepatocytes via LEF-1 through the Wnt pathway at the premalignant stage of HCC [55]. Also, high HBsAg levels were associated with late recurrence (after 2 years) after curative resection in HBV-related HCC [56]. So, HBsAg might use a similar action to affect ECC.

In general, our meta-analysis results were similar to those recently published by others about this subject [57]. However, this meta-analysis has several weaknesses that should be considered. First, the included studies were all observational studies that might introduce selection and recall biases. Second, lots of results were based on the random-effect model analysis, which might not reduce the strength of evidence. Third, a small number of studies were used to analyze the HBV infection status and the risk of cancer. Finally, the included studies were mostly from China. Thus, in the future, more studies from other counties need to be performed to explain the link between HBV infection and risk of CCA.

\section{Conclusion}

This study suggests that HBV infection is associated with an increased risk of CCA in Asia. The two HBV infection models ( $\mathrm{HBs} \mathrm{Ag}+/ \mathrm{HBcAb}+$ and $\mathrm{HBs} \mathrm{Ag}-/ \mathrm{HBcAb}+$ ) increase the risk of CCA, while the model of $\mathrm{HBs} \mathrm{Ag}-/ \mathrm{HBcAb}+$ increases the risk of ICC. More studies, especially from low epidemic areas, were needed to explore the connection between HBV infection model and CCA risk.

\section{Competing Interests}

On behalf of all authors, the corresponding author states that there is no conflict of interests.

\section{Authors' Contributions}

Hao Zhang and Biqing Zhu collected the data. Biqing Zhu did the statistical analysis. Hao Zhang wrote the article. He Zhang and Jianxin Liang contributed to conception and design of 


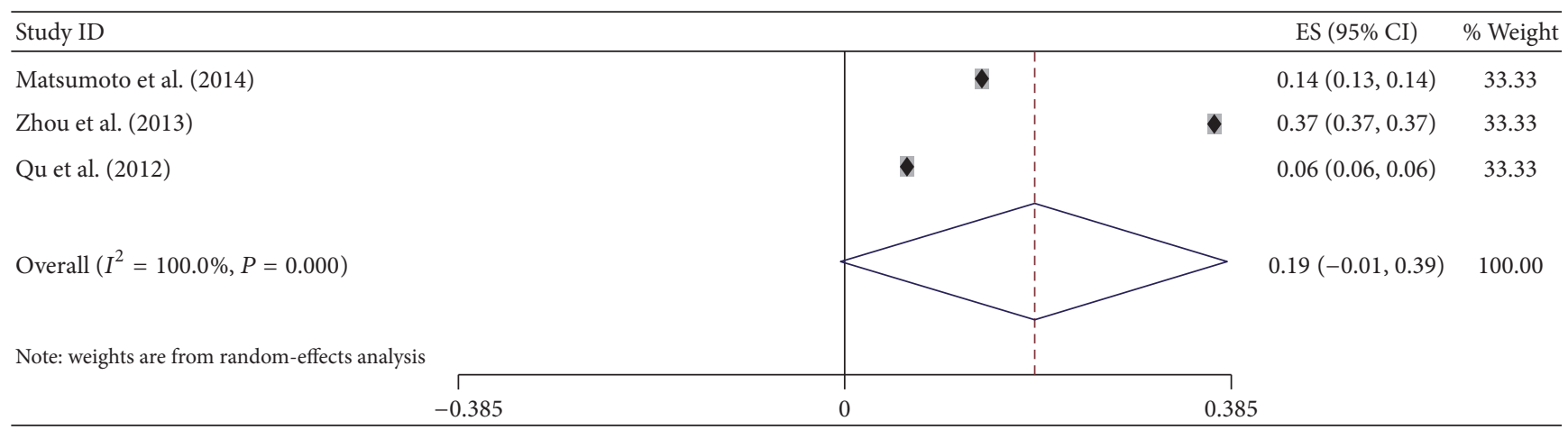

(a)

\begin{tabular}{l} 
Study ID \\
\hline Lee et al. (2015) \\
Chang et al. (2013) \\
Zhou et al. (2013) \\
Wu et al. (2012) \\
Tao et al. (2010) \\
Hsing et al. (2008) \\
Overall $\left(I^{2}=88.6 \%, P=0.000\right)$
\end{tabular}

(b)

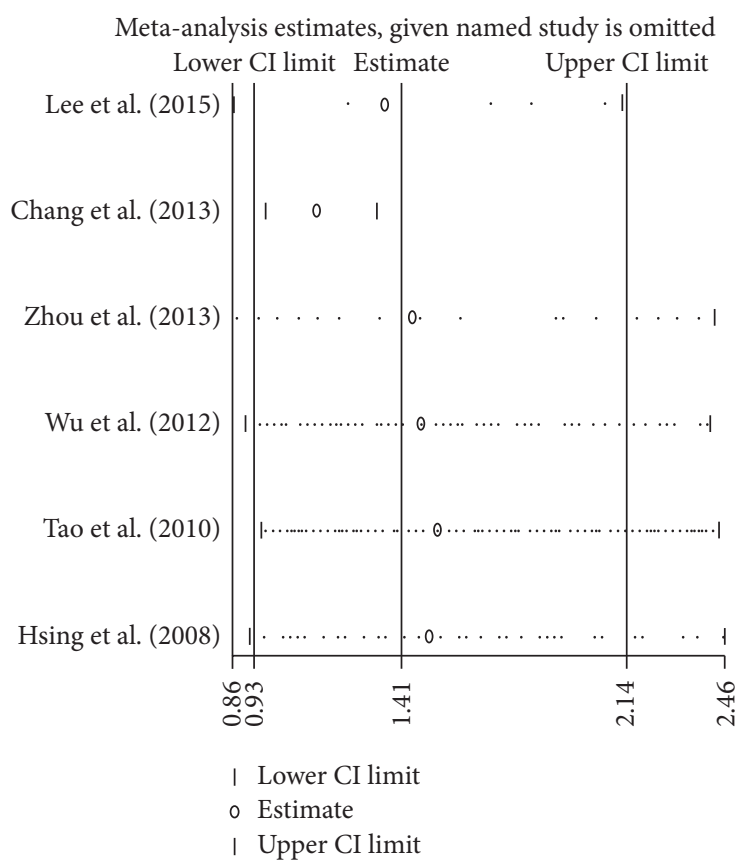

(c)

FIgure 4: Meta-analysis of the association between HBV infection and ECC. (a) Pooled incidence of ECC in Asia; (b) forest plots of the association between HBV infection and ECC with unadjusted OR; and (c) sensitivity analysis of the association between HBV infection and ECC. 


\begin{tabular}{|c|c|c|c|}
\hline Study ID & & OR $(95 \% \mathrm{CI})$ & \% Weight \\
\hline Wu et al. (2012) & $\longrightarrow$ & $7.90(4.52,13.82)$ & 55.05 \\
\hline Tao et al. (2010) & & $5.57(2.75,11.31)$ & 44.95 \\
\hline Overall $\left(I^{2}=0.0 \%, P=0.447\right)$ & & $6.86(4.42,10.63)$ & 100.00 \\
\hline 0.0724 & 13.8 & & \\
\hline
\end{tabular}

(a)

\begin{tabular}{|c|c|c|c|}
\hline Study ID & & OR $(95 \% \mathrm{CI})$ & $\%$ Weight \\
\hline Wu et al. (2012) & $\rightarrow \frac{1}{1}$ & $1.25(0.89,1.76)$ & 58.98 \\
\hline Li et al. (2014) & $\longrightarrow$ & $2.38(1.27,4.44)$ & 11.71 \\
\hline Tao et al. (2010) & $\rightarrow$ & $1.35(0.84,2.17)$ & 29.31 \\
\hline Overall $\left(I^{2}=37.4 \%, P=0.202\right)$ & & $1.41(1.09,1.82)$ & 100.00 \\
\hline 0.225 & 4.4 & & \\
\hline
\end{tabular}

(b)

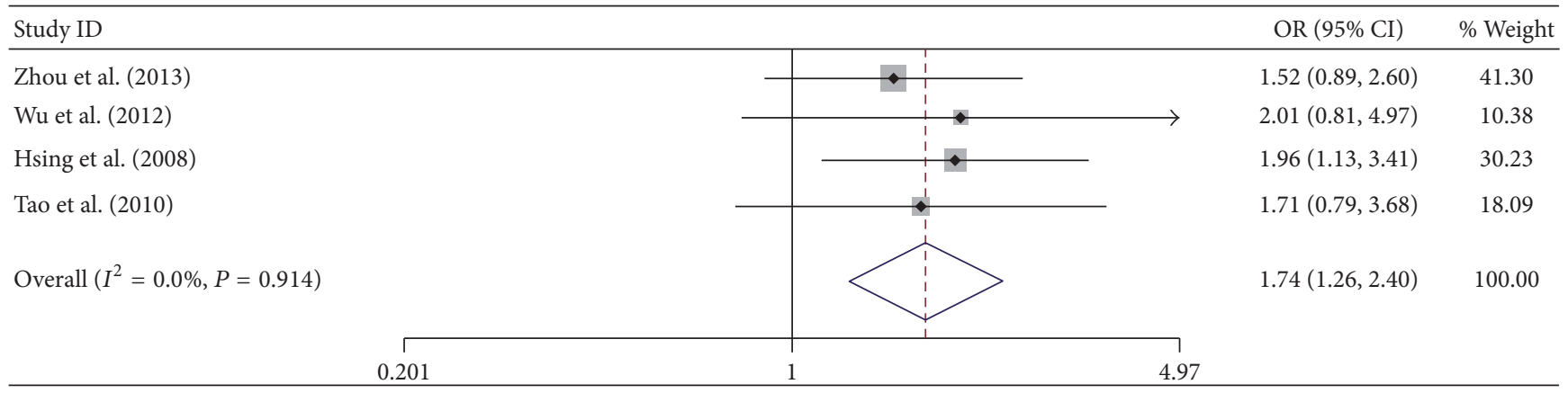

(c)

Meta-analysis estimates, given named study is omitted

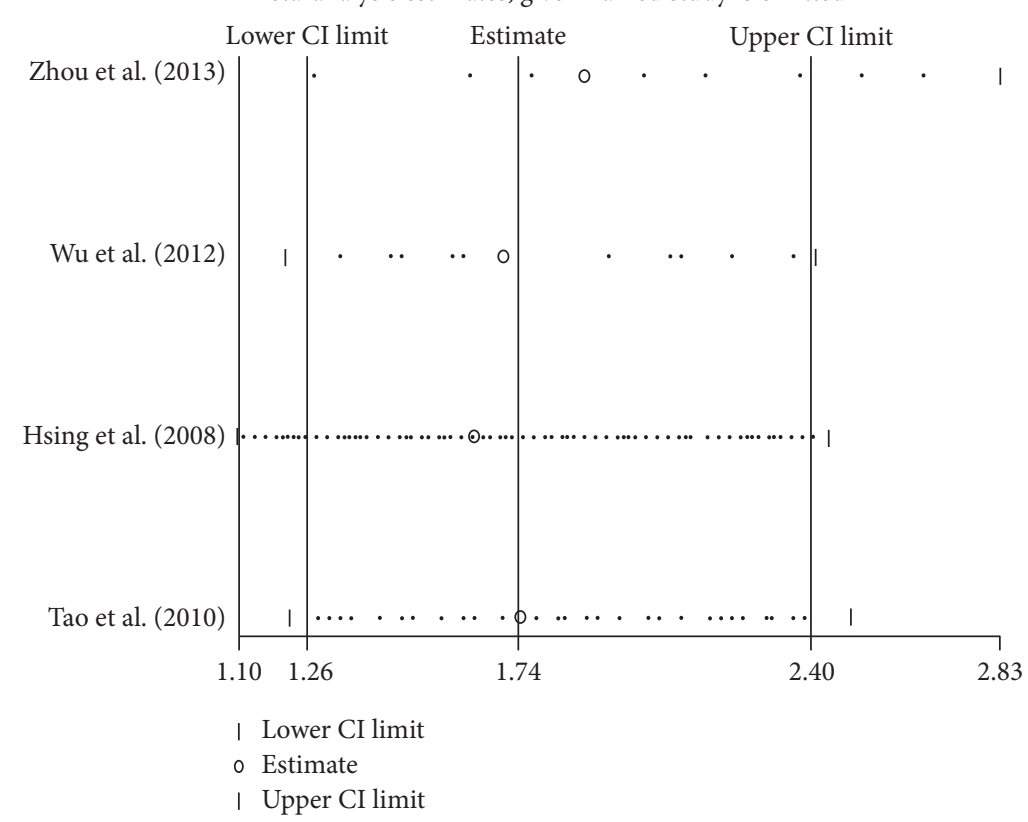

(d)

Figure 5: Continued. 


\begin{tabular}{l} 
Study ID \\
\hline Zhou et al. (2013) \\
Wu et al. (2012) \\
Hsing et al. (2008) \\
Tao et al. (2010)
\end{tabular}

(e)

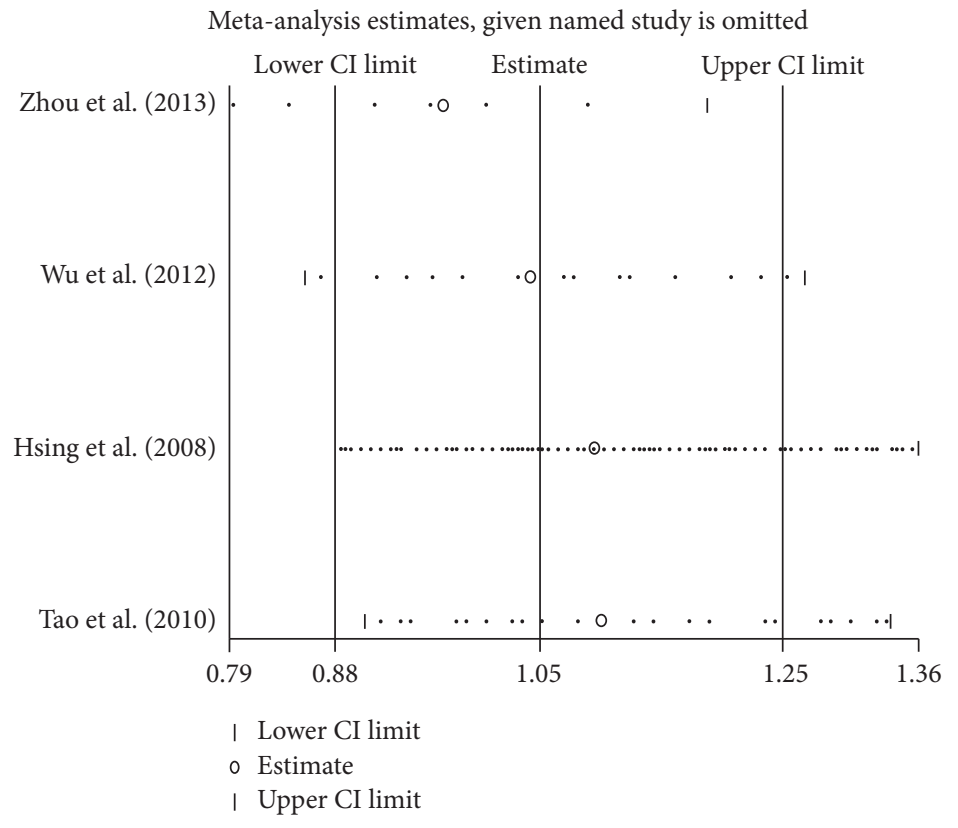

(f)

FIgURE 5: Meta-analysis of the association between HBV infection models and cancer. (a) Forest plots of the association between $\mathrm{HBsAg}+/ \mathrm{HBcAb}+$ and ICC; (b) forest plots of the association between $\mathrm{HBsAg}-/ \mathrm{HBcAb}+$ and ICC; (c) forest plots of the association between $\mathrm{HBsAg}+/ \mathrm{HBcAb}+$ and ECC; (d) sensitivity analysis of the association between HBsAg+/HBcAb+ and ECC; (e) forest plots of the association between $\mathrm{HBsAg}-/ \mathrm{HBcAb}+$ and ICC; and (f) sensitivity analysis of the association between $\mathrm{HBs} \mathrm{Ag}-/ \mathrm{HBcAb}+\mathrm{and} \mathrm{ECC}$.

the study and revised the article. Wenting Zeng is guarantor of the article. All authors approved the final version of the manuscript. Hao Zhang and Biqing Zhu contributed equally to this work.

\section{Acknowledgments}

This study was supported by Science and Technology Planning Project of Guangdong Province to Wenting Zeng (2013B022000101).

\section{References}

[1] S. A. Khan, B. R. Davidson, R. D. Goldin et al., "Guidelines for the diagnosis and treatment of cholangiocarcinoma: an update," Gut, vol. 61, no. 12, pp. 1657-1669, 2012.
[2] S. A. Khan, H. C. Thomas, B. R. Davidson, and S. D. TaylorRobinson, "Cholangiocarcinoma," The Lancet, vol. 366, no. 9493, pp. 1303-1314, 2005.

[3] S. Rizvi and G. J. Gores, "Pathogenesis, diagnosis, and management of cholangiocarcinoma," Gastroenterology, vol. 145, no. 6, pp. 1215-1229, 2013.

[4] T. Patel, "Worldwide trends in mortality from biliary tract malignancies," BMC Cancer, vol. 2, article 10, 2002.

[5] R. Al-Bahrani, Y. Abuetabh, N. Zeitouni, and C. Sergi, "Cholangiocarcinoma: risk factors, environmental influences and oncogenesis," Annals of Clinical and Laboratory Science, vol. 43, no. 2, pp. 195-210, 2013.

[6] Y. H. Shaib, H. B. El-Serag, J. A. Davila, R. Morgan, and K. A. McGlynn, "Risk factors of intrahepatic cholangiocarcinoma in the United States: a case-control study," Gastroenterology, vol. 128, no. 3, pp. 620-626, 2005. 
[7] "EASL Clinical Practice Guidelines: management of chronic hepatitis B virus infection," Journal of Hepatology, vol. 57, no. 1, pp. 167-185, 2012.

[8] T. Li, S.-K. Wang, J. Zhou et al., "Positive HBcAb is associated with higher risk of early recurrence and poorer survival after curative resection of HBV-related HCC," Liver International, vol. 36, no. 2, pp. 284-292, 2016.

[9] L. Mozessohn, K. K. W. Chan, J. J. Feld, and L. K. Hicks, "Hepatitis B reactivation in $\mathrm{HBsAg}$-negative/HBcAb-positive patients receiving rituximab for lymphoma: a meta-analysis," Journal of Viral Hepatitis, vol. 22, no. 10, pp. 842-849, 2015.

[10] D. F. Stroup, J. A. Berlin, S. C. Morton et al., "Meta-analysis of observational studies in epidemiology: a proposal for reporting," Journal of the American Medical Association, vol. 283, no. 15, pp. 2008-2012, 2000.

[11] K. Matsumoto, T. Onoyama, S. Kawata et al., "Hepatitis B and $\mathrm{C}$ virus infection is a risk factor for the development of cholangiocarcinoma," Internal Medicine, vol. 53, no. 7, pp. 651654, 2014.

[12] X. Luo, L. Yuan, Y. Wang, R. Ge, Y. Sun, and G. Wei, "Survival outcomes and prognostic factors of surgical therapy for all potentially resectable intrahepatic cholangiocarcinoma: A Large Single-Center Cohort Study," Journal of Gastrointestinal Surgery, vol. 18, no. 3, pp. 562-572, 2014.

[13] R.-Q. Liu, S.-J. Shen, X.-F. Hu, J. Liu, L.-J. Chen, and X.-Y. Li, "Prognosis of the intrahepatic cholangiocarcinoma after resection: hepatitis B virus infection and adjuvant chemotherapy are favorable prognosis factors," Cancer Cell International, vol. 13, no. 1, article 99, 2013.

[14] X. Yin, S.-S. Zheng, B.-H. Zhang et al., "Elevation of serum $\boldsymbol{\gamma}$ glutamyltransferase as a predictor of aggressive tumor behaviors and unfavorable prognosis in patients with intrahepatic cholangiocarcinoma: analysis of a large monocenter study," European Journal of Gastroenterology and Hepatology, vol. 25, no. 12, pp. 1408-1414, 2013.

[15] Y. Zhou, Q. Zhou, Q. Lin et al., "Evaluation of risk factors for extrahepatic cholangiocarcinoma: ABO blood group, hepatitis B virus and their synergism," International Journal of Cancer, vol. 133, no. 8, pp. 1867-1875, 2013.

[16] Z.-F. Wu, N. Yang, D.-Y. Li, H.-B. Zhang, and G.-S. Yang, "Characteristics of intrahepatic cholangiocarcinoma in patients with hepatitis B virus infection: clinicopathologic study of resected tumours," Journal of Viral Hepatitis, vol. 20, no. 5, pp. 306-310, 2013.

[17] C.-H. Lee, S.-Y. Hsieh, C.-J. Chang, and Y.-J. Lin, "Comparison of clinical characteristics of combined hepatocellularcholangiocarcinoma and other primary liver cancers," Journal of Gastroenterology and Hepatology, vol. 28, no. 1, pp. 122-127, 2013.

[18] S. Barusrux, C. Nanok, W. Puthisawas, C. Pairojkul, and Y. Poovorawan, "Viral hepatitis B, C infection and genotype distribution among cholangiocarcinoma patients in northeast Thailand," Asian Pacific Journal of Cancer Prevention, vol. 13, no. 1, pp. 83-87, 2012.

[19] X. Yin, B.-H. Zhang, S.-J. Qiu et al., "Combined hepatocellular carcinoma and cholangiocarcinoma: clinical features, treatment modalities, and prognosis," Annals of Surgical Oncology, vol. 19, no. 9, pp. 2869-2876, 2012.

[20] Z. Qu, N. Cui, M. Qin, and X. Wu, "Epidemiological survey of biomarkers of hepatitis virus in patients with extrahepatic cholangiocarcinomas," Asia-Pacific Journal of Clinical Oncology, vol. 8, no. 1, pp. 83-87, 2012.
[21] Y. Wu, T. Wang, S. Ye et al., "Detection of hepatitis B virus DNA in paraffin-embedded intrahepatic and extrahepatic cholangiocarcinoma tissue in the northern Chinese population," Human Pathology, vol. 43, no. 1, pp. 56-61, 2012.

[22] B.-G. Jiang, R.-L. Ge, L.-L. Sun, M. Zong, G.-T. Wei, and Y.-J. Zhang, "Clinical parameters predicting survival duration after hepatectomy for intrahepatic cholangiocarcinoma," Canadian Journal of Gastroenterology, vol. 25, no. 11, pp. 603-608, 2011.

[23] H.-B. Zhou, H. Wang, Y.-Q. Li et al., "Hepatitis B virus infection: a favorable prognostic factor for intrahepatic cholangiocarcinoma after resection," World Journal of Gastroenterology, vol. 17, no. 10, pp. 1292-1303, 2011.

[24] H. Park, K. H. Choi, S.-B. Choi et al., "Clinicopathological characteristics in combined hepatocellular-cholangiocarcinoma: a single center study in Korea," Yonsei Medical Journal, vol. 52, no. 5, pp. 753-760, 2011.

[25] H.-B. Zhou, H. Wang, D.-X. Zhou et al., "Etiological and clinicopathologic characteristics of intrahepatic cholangiocarcinoma in young patients," World Journal of Gastroenterology, vol. 16, no. 7, pp. 881-885, 2010.

[26] Y.-M. Zhou, J.-M. Yang, B. Li et al., "Clinicopathologic characteristics of intrahepatic cholangiocarcinoma in patients with positive serum a-fetoprotein," World Journal of Gastroenterology, vol. 14, no. 14, pp. 2251-2254, 2008.

[27] H.-Q. Zuo, L.-N. Yan, Y. Zeng et al., "Clinicopathological characteristics of 15 patients with combined hepatocellular carcinoma and cholangiocarcinoma," Hepatobiliary and Pancreatic Diseases International, vol. 6, no. 2, pp. 161-165, 2007.

[28] T. Fukuhara, G. B. Sharp, T. Mizuno et al., "Liver cancer in atomic-bomb survivors: histological characteristics and relationships to radiation and hepatitis B and C viruses," Journal of Radiation Research, vol. 42, no. 2, pp. 117-130, 2001.

[29] W.-S. Lee, K.-W. Lee, J.-S. Heo et al., "Comparison of combined hepatocellular and cholangiocarcinoma with hepatocellular carcinoma and intrahepatic cholangiocarcinoma," Surgery Today, vol. 36, no. 10, pp. 892-897, 2006.

[30] A. Pinyosophon and V. Wiwanitkit, "The prevalence of hepatitis B seropositivity among patients with cholangiocarcinoma," Viral Immunology, vol. 15, no. 4, pp. 655-657, 2002.

[31] Y. Asayama, S.-I. Aishima, K.-I. Taguchi et al., "Coexpression of neural cell adhesion molecules and bcl-2 in intrahepatic cholangiocarcinoma originated from viral hepatitis: relationship to atypical reactive bile ductule," Pathology International, vol. 52, no. 4, pp. 300-306, 2002.

[32] B. S. Lee, E.-C. Park, S. W. Park, C. M. Nam, and J. Roh, "Hepatitis $B$ virus infection, diabetes mellitus, and their synergism for cholangiocarcinoma development: a casecontrol study in Korea," World Journal of Gastroenterology, vol. 21, no. 2, pp. 502510, 2015.

[33] Y.-M. Zhou, X.-F. Zhang, L.-P. Wu, C.-J. Sui, and J.-M. Yang, "Risk factors for combined hepatocellular-cholangiocarcinoma: a hospital-based case-control study," World Journal of Gastroenterology, vol. 20, no. 35, pp. 12615-12620, 2014.

[34] Y. Q. Li, H. Wang, D. P. Li et al., "Occult hepatitis B virus infection in Chinese cryptogenic intrahepatic cholangiocarcinoma patient population," Journal of Clinical Gastroenterology, vol. 48, no. 10, pp. 878-882, 2014.

[35] J. S. Chang, C.-R. Tsai, and L.-T. Chen, "Medical risk factors associated with cholangiocarcinoma in Taiwan: A PopulationBased Case-Control Study," PLoS ONE, vol. 8, no. 7, article e69981, 2013. 
[36] N.-F. Peng, L.-Q. Li, X. Qin et al., "Evaluation of risk factors and clinicopathologic features for intrahepatic cholangiocarcinoma in Southern China: a possible role of Hepatitis B virus," Annals of Surgical Oncology, vol. 18, no. 5, pp. 1258-1266, 2011.

[37] W.-K. Cai, H. Sima, B.-D. Chen, and G.-S. Yang, "Risk factors for hilar cholangiocarcinoma: a case-control study in China," World Journal of Gastroenterology, vol. 17, no. 2, pp. 249-253, 2011.

[38] P. Srivatanakul, S. Honjo, P. Kittiwatanachot, A. Jedpiyawongse, T. Khuhaprema, and M. Miwa, "Hepatitis viruses and risk of cholangiocarcinoma in northeast Thailand," Asian Pacific Journal of Cancer Prevention, vol. 11, no. 4, pp. 985-988, 2010.

[39] H. Zhou, H. Wang, D. Zhou et al., "Hepatitis B virus-associated intrahepatic cholangiocarcinoma and hepatocellular carcinoma may hold common disease process for carcinogenesis," European Journal of Cancer, vol. 46, no. 6, pp. 1056-1061, 2010.

[40] L.-Y. Tao, X.-D. He, Q. Qu et al., "Risk factors for intrahepatic and extrahepatic cholangiocarcinoma: case-control study in China," Liver International, vol. 30, no. 2, pp. 215-221, 2010.

[41] C. H. Lee, C. J. Chang, Y. J. Lin, C. N. Yeh, M. F. Chen, and S. Y. Hsieh, "Viral hepatitis-associated intrahepatic cholangiocarcinoma shares common disease processes with hepatocellular carcinoma," British Journal of Cancer, vol. 100, no. 11, pp. 17651770, 2009.

[42] Y.-M. Zhou, Z.-F. Yin, J.-M. Yang et al., "Risk factors for intrahepatic cholangiocarcinoma: a case-control study in China," World Journal of Gastroenterology, vol. 14, no. 4, pp. 632-635, 2008.

[43] A. W. Hsing, M. Zhang, A. Rashid et al., "Hepatitis B and C virus infection and the risk of biliary tract cancer: a population-based study in China," International Journal of Cancer, vol. 122, no. 8, pp. 1849-1853, 2008.

[44] T. Y. Lee, S. S. Lee, S. W. Jung et al., "Hepatitis B virus infection and intrahepatic cholangiocarcinoma in Korea: A Case-Control Study," American Journal of Gastroenterology, vol. 103, no. 7, pp. 1716-1720, 2008.

[45] S. Yamamoto, S. Kubo, S. Hai et al., "Hepatitis C virus infection as a likely etiology of intrahepatic cholangiocarcinoma," Cancer Science, vol. 95, no. 7, pp. 592-595, 2004.

[46] G. A. Wells, B. Shea, D. O'Connell et al., The Newcastle-Ottawa Scale (NOS) for Assessing the Quality of Nonrandomised Studies in Meta-analyses, Ottawa Hospital Research Institute, Ottawa, Canada, 2012.

[47] Q. Wu, X.-D. He, L. Yu, W. Liu, and L.-Y. Tao, "The metabolic syndrome and risk factors for biliary tract cancer: a case-control study in China," Asian Pacific Journal of Cancer Prevention, vol. 13, no. 5, pp. 1963-1969, 2012.

[48] R. Sankaranarayanan, K. Ramadas, and Y.-L. Qiao, "Managing the changing burden of cancer in Asia," BMC Medicine, vol. 12, no. 1, article 3, 2014.

[49] Y. Zhou, Y. Zhao, B. Li et al., "Hepatitis viruses infection and risk of intrahepatic cholangiocarcinoma: evidence from a metaanalysis," BMC Cancer, vol. 12, article 289, 2012.

[50] M. R. Alison, "Liver stem cells: implications for hepatocarcinogenesis," Stem Cell Reviews, vol. 1, no. 3, pp. 253-260, 2005.

[51] X.-F. Liu, S.-Q. Zou, and F.-Z. Qiu, "Pathogenesis of cholangiocarcinoma in the porta hepatis and infection of hepatitis virus," Hepatobiliary and Pancreatic Diseases International, vol. 2, no. 2, pp. 285-289, 2003.

[52] M. Tomimatsu, N. Ishiguro, M. Taniai et al., "Hepatitis $C$ virus antibody in patients with primary liver cancer (hepatocellular carcinoma, cholangiocarcinoma, and combined hepatocellular- cholangiocarcinoma) in Japan," Cancer, vol. 72, no. 3, pp. 683688, 1993.

[53] H. Tanaka, Y. Iwasaki, K. Nouso et al., "Possible contribution of prior hepatitis $\mathrm{B}$ virus infection to the development of hepatocellular carcinoma," Journal of Gastroenterology and Hepatology, vol. 20, no. 6, pp. 850-856, 2005.

[54] A. Reddy, E. May, M. Ehrinpreis, and M. Mutchnick, "Latent hepatitis B is a risk factor for hepatocellular carcinoma in patients with chronic hepatitis C," World Journal of Gastroenterology, vol. 19, no. 48, pp. 9328-9333, 2013.

[55] X. Tian, J. Li, Z.-M. Ma, C. Zhao, D.-F. Wan, and Y.-M. Wen, "Role of hepatitis B surface antigen in the development of hepatocellular carcinoma: regulation of lymphoid enhancerbinding factor 1," Journal of Experimental and Clinical Cancer Research, vol. 28, no. 1, article 58, 2009.

[56] W. Sohn, Y.-H. Paik, J. M. Kim et al., "HBV DNA and HBsAg levels as risk predictors of early and late recurrence after curative resection of HBV-related hepatocellular carcinoma," Annals of Surgical Oncology, vol. 21, no. 7, pp. 2429-2435, 2014.

[57] M. Li, J. Li, P. Li et al., "Hepatitis B virus infection increases the risk of cholangiocarcinoma: a meta-analysis and systematic review," Journal of Gastroenterology and Hepatology, vol. 27, no. 10, pp. 1561-1568, 2012. 


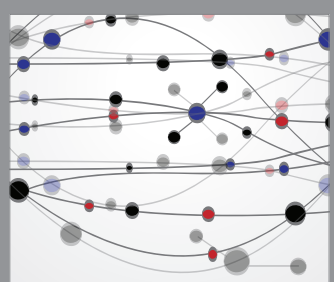

The Scientific World Journal
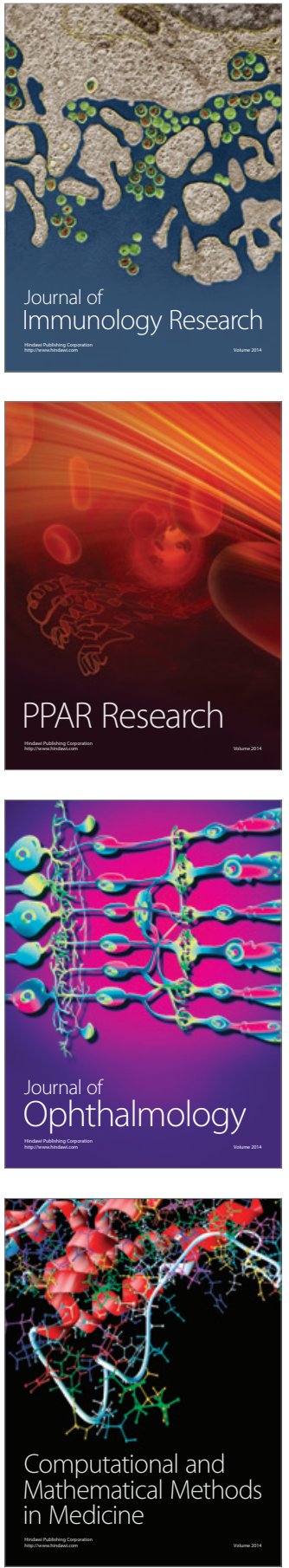

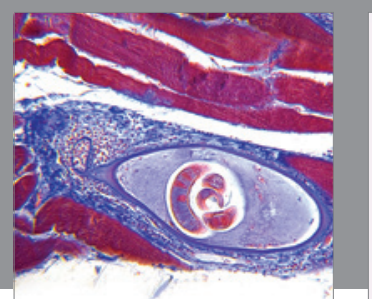

Gastroenterology Research and Practice

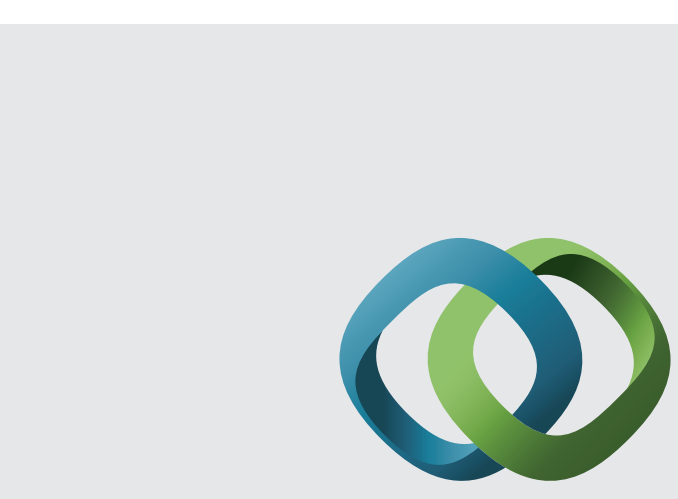

\section{Hindawi}

Submit your manuscripts at

http://www.hindawi.com
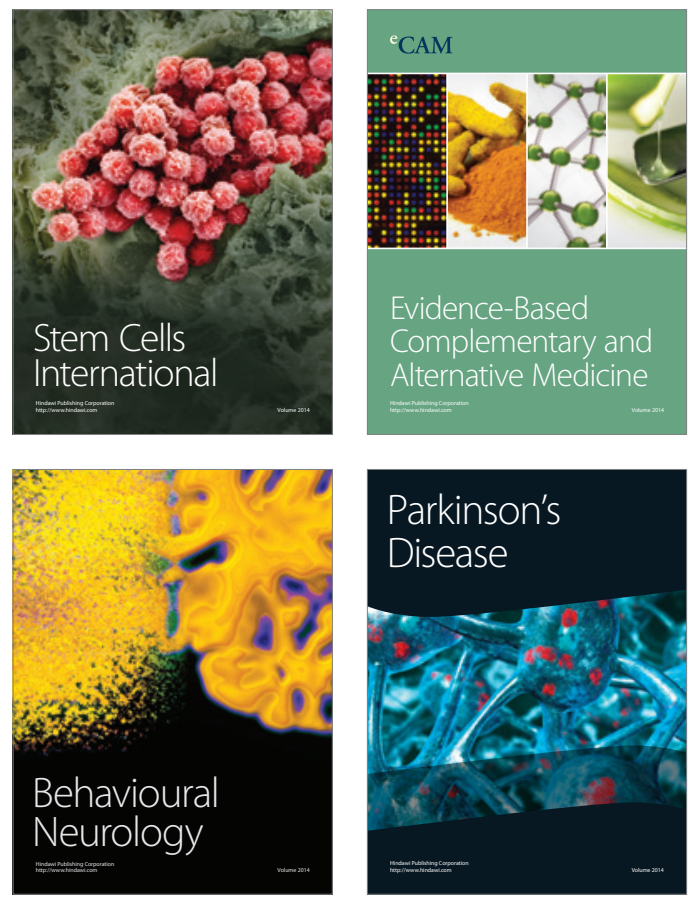
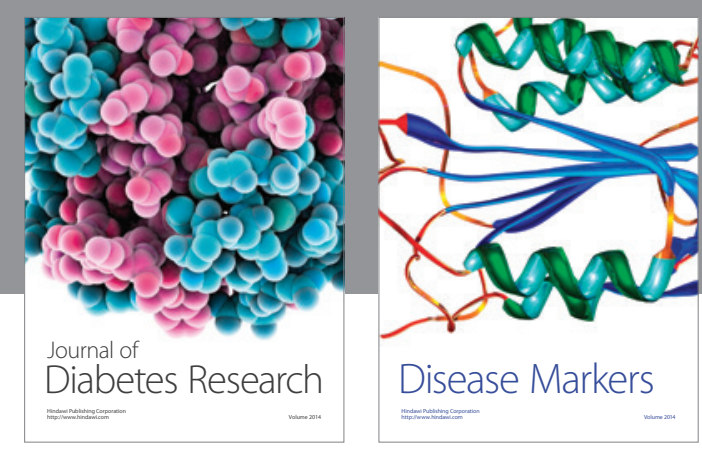

Disease Markers
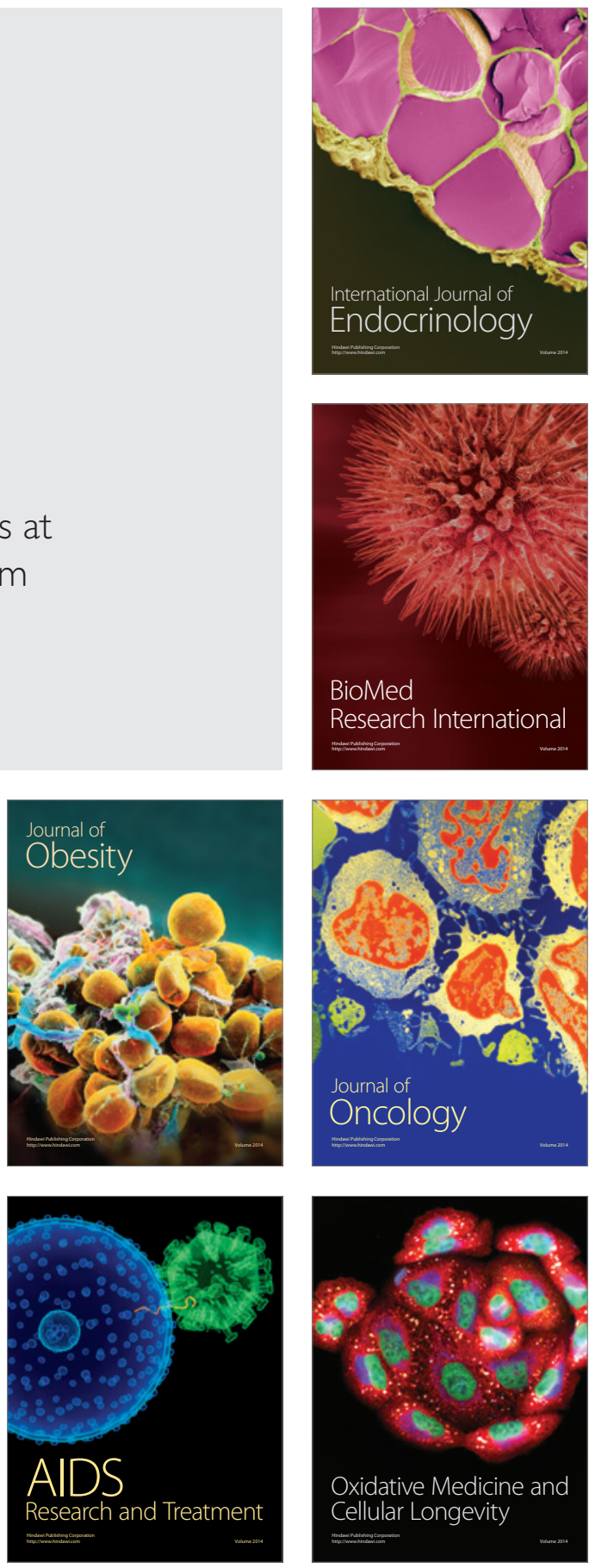